\title{
COMPARATIVE STUDY OF MATERNAL OUTCOME IN EMERGENCY VERSUS ELECTIVE CAESAREAN SECTION
}

\author{
R. Indira Priyadarshini', K. Saraswathi², V. Ratna Kumari ${ }^{3}$
}

\author{
${ }^{1}$ Assistant Professor, Department of Obstetrics and Gynaecology, ACSR Govt. Medical College, MCH Hospital, Nellore. \\ ${ }^{2}$ Associate Professor, Department of Obstetrics and Gynocology, Niloufer Hospital, Hyderabad. \\ ${ }^{3}$ Professor, Department of Obstetrics and Gynaecology, Niloufer Hospital, Hyderabad.
}

\begin{abstract}
OBJECTIVE: The aim of this study was to find out the maternal outcome in emergency and elective caesarean sections and to compare the intraoperative and postoperative maternal complications in emergency and elective caesarean sections.

METHOD: In this hospital based descriptive study 100 cases of emergency caesarean section (EMCS) were compared with 100 cases of elective caesarean section (ELCS) over a period of 2 years in the department of obstetrics and gynaecology in Niloufer Hospital, Hyderabad. The pregnant women of any parity or age were admitted through OPD or emergency during the study period. Data collection included maternal age, parity, indication for caesarean section, blood loss during surgery, number of blood transfusions, atonic PPH, bladder and bowel injuries, incidence of postoperative complications including PPH, prolonged hospital stay, wound sepsis and dehiscence.

RESULTS: In Emergency caesarian group thirty cases (30\%) were admitted through OPD and 70 cases (70\%) through emergency admissions. In elective caesarean group 80 cases (80\%) were admitted through OPD and 20 cases (20\%) were admitted through emergency. Majority of caesarean sections in both groups were done in the age group between 20-30 years. More caesarean sections were done in multigravida than in primis in both the groups. Higher rate of intraoperative complications were found in emergency caesarean section than in elective caesarean sections. Haemorrage was more common in emergency caesarean section $(37 \%)$ than in elective caesarean section (14\%).The most common indications for EMCS were two previous sections in labour, one previous section in labour, PROM, failure to progress, breech presentation in labour and foetal distress. The most common indications for ELCS were previous section, breech presentation and CPD. There were higher incidence of maternal intraoperative complications in EMCS group compared to the ELCS group. There was significant difference seen in the length of postoperative hospital stay, urinary tract infection, wound sepsis and burst abdomen showing higher incidence of postoperative complication s in EMCS than in ELCS.
\end{abstract}

CONCLUSION: Maternal intraoperative and postoperative complications were found to be more in EMCS than in ELCS.

KEYWORDS: Emergency Caesarian Section, Elective Caesarian Section, Maternal Outcome, Haemorrhage.

HOW TO CITE THIS ARTICLE: R. Indira Priyadarshini, K. Saraswathi, V. Ratna Kumari. "Comparative Study of Maternal Outcome in Emergency Versus Elective Caesarean Section". Journal of Evolution of Medical and Dental Sciences 2015; Vol. 4, Issue 91, November 12; Page: 15637-15639, DOI: 10.14260/jemds/2015/2249.

INTRODUCTION: Caesarean delivery is defined as the birth of a foetus through an incision in the abdominal wall (Laparotomy) and uterine wall (Hysterotomy) after 20 weeks of gestational age. Caesarean section is a lifesaving procedure done where vaginal delivery is considered inappropriate or dangerous to either the baby or mother. With the advances in anaesthetic services, improved surgical techniques, availability of blood transfusion facilities and antibiotics, the morbidity and mortality of this procedure has come down considerably. This has emboldened the Obstetrician to perform more and more caesarean sections.

Over the past 20 years there has been an increase the rate of caesarean all over the world. Some of the contributing factors are decreased rate of vaginal births after caesarean section, assisted breech deliveries, patient perception that caesarean section is safer for the foetus, fear of labour pains,

Financial or Other, Competing Interest: None.

Submission 23-10-2015, Peer Review 24-10-2015,

Acceptance 31-10-2015, Published 10-11-2015.

Corresponding Author:

Dr. K. Saraswathi

Associate Professor,

Department of Obstetrics and Gynaecology,

Niloufer Hospital, Hyderabad. Telangana State.

E-mail: saraswathikokkirala@gmail.com

DOI:10.14260/jemds/2015/2249. pelvic floor damage and socio-cultural influence (e.g. choosing auspicious time). An unindicated caesarean section in a low risk uncomplicated pregnancy carries eight fold higher mortality than vaginal delivery, eight to twelve times higher morbidity and a higher incidence of complications in subsequent pregnancy.

Elective caesarean is defined when the procedure is done after proper planning and preoperative preparation during pregnancy to ensure best quality of obstetric care, Anaesthesia, neonatal resuscitation and blood transfusion facilities. Emergency caesarian section is defined as the one that is performed as soon as possible whenever obstetric emergency arises. Maternal and foetal complications are more with emergency caesarian section than in elective caesarian section. The objective of the study was to compare the maternal outcome in emergency versus elective caesarian section.

METHODS: In this hospital based descriptive study 100 cases of EMCS were compared with 100 cases of ELCS for maternal complications over a period of two years from July 2011 to June 2013.The study was carried out in the department of obstetrics and gynaecology, Niloufer Hospital, Hyderabad.

Pregnant patients of any age and parity admitted through OPD or emergency were included in the study. 
Patients with classical caesarian section were excluded from the study.

Patients were divided into two groups based on those undergoing EMCS and those undergoing ELCS. Detailed obstetric, medical and surgical history taken and general and obstetric examination were done. Indication for caesarean section noted. Necessary investigations were performed. Preoperative care included evaluation by anaesthetist, informed consent and reserving compatible blood.

Injection Ranitidine $50 \mathrm{mg}$ i.v. and injection metoclopramide $10 \mathrm{mg}$ i.v. given before surgery. For ELCS oral intake stopped 8 hours before surgery. Intraoperative data collected included duration of surgery, anaesthetic complications, haemorrhage, $\mathrm{PPH}$, bladder and bowel injuries, uterine angle extension of incision, caesarian hysterectomy and intraoperative blood transfusions.

Postoperative data collected included duration of postoperative hospital stay, PPH, anaemia, blood transfusions, urinary tract infections, wound sepsis and burst abdomen.

RESULTS: Majority of the caesarian sections in both the groups (Emergency and Elective) were done in the age group 20-30 years with 78\% in the EMLS group and $90 \%$ in the ELCS group. More caesarians were done in multigravidas than in primis. In EMCS $70 \%$ were admitted on emergency basis and in ELCS group 80\% were admitted through OPD (Table 1). The most common indication for EMCS was two previous caesarian sections in labour $(15 \%)$ one previous caesarian section in labour, PROM (12\%), dystocia (10\%), breech in labour $(10 \%)$, pre-eclampsia $(10 \%)$, foetal distress $(8 \%)$ and IUGR, APH, eclampsia, failed induction in $5 \%$ each.

The usual indication in ELCS were two previous caesarian sections (40\%), one previous caesarian section (24\%), breech (13\%), CPD (10\%) and IUGR (10\%) (Table 2).

High rate of intraoperative complications were found in EMCS than in ELCS. Haemorrhage was more common in EMCS (37\%) than in ELCS (14\%). Need for intraoperative blood transfusion in EMCS was 35\% and in ELCS it was $10 \%(\mathrm{p}=0.005)$ Atonic uterus was more in EMCS $(12 \%)$ than in ELCS (4\%) $p=0.037$.Three cases of bladder injury were seen in EMCS and none in ELCS $(p=0.08)$. Table 3

With regard to Postoperative maternal complications need for postoperative blood transfusion was found to be higher in EMCS $(30 \%)$ than in ELCS $(10 \%)$. ( $p=0.000)$.

PPH occurred in $28 \%$ cases in EMCS and in $14 \%$ cases in ELCS ( $\mathrm{p}=0.014)$.Wound infection occurred more in EMCS $(18 \%)$ than in ELCS $(6 \%) p=0.009$.

UTI was more often seen EMCS than in ELCS. Burst abdomen was seen in 2 cases of EMCS group and none had burst abdomen in ELCS group. Postoperative stay of more than one week was seen in $20 \%$ of cases of EMCS whereas it was seen in $5 \%$ of cases of ELCS (0.001) Table 4.

DISCUSSION: From 1970 to 2007 the caesarian delivery rate in the United States rose from $4.4 \%$ to $31.8 \%$ of all deliveries.

The Indian council of medical research on 33tertiary care institutions noted that average caesarian section rate increased from $21.8 \%$ in $1993-94$ to $25.4 \%$ in $1998-99$. In Medical colleges and Teaching Hospitals in India the overall rate of caesarian deliveries are $24.4 \%$. In our study spanning over 2 years (July 2011-June 2013) in the department of Obstetrics and Gynaecology at Niloufer Hospital caesarian birth rate was $40 \%$.
The high rate is because of the reason that this hospital is a tertiary care centre for neonatal medical and surgical emergencies which makes it a referral centre for various high risk pregnancies.

Most of the caesarian sections were done in the age group of $20-30$ years $(78 \%$ and $90 \%$ in EMCS and ELCS respectively) comparable to the study of Asifa Ghazi et al.(1) and D A Vaughan et al.(2) In the index study percentage of multigravidas in both the groups were more $(66 \%$ and $88 \%$ in EMCS and ELCS respectively) than primigravidas (34\% and $12 \%$ in EMCS and ELCS respectively) comparable with the study of Lulu Al Nuaim et al.(3) This is because the usual indications of caesarian section in both the groups were previous one or two caesarian section.

In the present study $80 \%$ of the ELCS cases were admitted through OPD while $20 \%$ were through emergency admission. In the EMCS group 70\% were emergency admissions and $30 \%$ were admitted through OPD which is statistically significant.

The most common indication of EMCS was previous two caesarian sections in labour $(15 \%)$ followed by one previous caesarian section $(12 \%)$, PROM $(12 \%)$, failure to progress (10\%), foetal distress (8\%) and obstructed labour $r(3 \%)$. Similar indications were noted in a study by Asifa Ghazi.Usual indications for ELCS were two previous sections (40\%) followed by one previous caesarian section (24\%), Breech presentation (13\%), CPD (10\%), IUGR (10\%). Similar indications were observed in a study done by Asifa Ghazi.

More intraoperative complications were found in EMCS than in ELCS. Haemorrhage was more common in EMCS $(37 \%)$ than in ELCS $(14 \%)(p=0.000)$. In a study done by Mehnaz Raeel et al.(4) in 2006-2007, hemorrhage was found in 58\% of EMCS group and $4 \%$ of ELCS group. This increased bleeding in EMCS group was due to the caesarian sections done after prolonged labour with stretched and edematous lower segment with impacted presented part causing extension of incision laterally into the uterine vessels. More patients in the EMCS group (35\%) needed intraoperative transfusions than in ELCS group $(10 \%)$ in our study $(\mathrm{p}=0.000)$. Study conducted by Asifa Ghazi reported $92 \%$ and $20 \%$ transfusion rates among EMCS and ELCS respectively.

In our Institute most of caesarian sections were done under regional anaesthesia. General anesthesia reserved for high risk cases and for prolonged surgeries. In our study difficult intubations were seen in $8 \%$ and $2 \%$ of cases in EMCS and ELCS group respectively. Asifa Ghazi et al reported difficult intubations in 14\% and $0 \%$ cases of EMCS and ELCS groups respectively. Bladder injury occurred in 3\% and $0 \%$ cases of EMCS and ELCS respectively. Mehnaaz Raees et al reported bladder injuries in $18 \%$ and $0 \%$ of their cases in EMCS and ELCS group respectively.

Atonic PPH was reported in $12 \%$ and $4 \%$ of cases in EMCS and ELCS groups respectively $(\mathrm{p}=0.037)$.Two patients required caesarian hysterectomy in EMCS group, one for placenta praevia and another for atonic uterus and none in ELCS group. Zindal Pramila et al reported caesarian hysterectomy in $8.6 \%$ of their cases of EMCS group. ${ }^{(5)}$

Postoperative complications were more in EMCS group than in ELCS group in our study. Postoperative blood transfusions were necessary in $30 \%$ and $10 \%$ of EMCS and ELCS groups respectively in our study which was statistically significant. 
Mehnaz Raeel et al(4), in a study reported postoperative blood transfusion in $62 \%$ and $16 \%$ cases in EMCS and ELCS groups respectively. Patients required blood transfusion due to increased intraoperative blood loss and PPH.PPH was reported in 28\% 14\% cases of EMCS and ELCS groups $\mathrm{p}=0.015$.Statistically significant urinary tract infections occurred in EMCS group (20\%) than in ELCS group (8\%). In a study conducted by Mehnaz Raees, UTI was reported in 24\% and $8 \%$ of EMCS and ELCS respectively.

Maaike A. P. C, Van Ham et al.(6) in a study conducted between 1983 and 1992 found UTI in 3\% of EMCS. Wound sepsis developed in $18 \%$ and $6 \%$ cases of EMCS and ELCS group respectively in the present study. Two cases from the EMCS group had burst abdomen. Samia Hassan et al.(7) also reported high incidence of wound infection in EMCS group than in ELCS group. 20\% and 5\% of patients from EMCS and ELCS groups respectively required prolonged postoperative hospital stay of more than a week in our study.

CONCLUSION: This study shows that maternal complications are more in EMCS group than in ELCS group. So cases which are decided for caesarian mode of delivery should have a planned repeat caesarean section to minimize the number of Emergency caesarian sections and its associated maternal complications.

\section{REFERENCES:}

1. Asifa ghazi, Farha karim, Ayesha Muhammad Hussain, Tehmina Ali,Shazia Jabbar, maternal morbidity in elective versus emergency at tertiary hospital in J of ayub med col Abbott 2012:24(1)

2. D A Vaughan J Cleary published online on June 12 2013D0I:10 1111/1471-0528.12311(261-68).

3. Lulu Al-Nuaim et al-outcome of emergency and elective caesarian sections Annals of Saudi Medicine volume 16 No 61996.

4. Mehnaaz Raees, Yasmeen S, Jabeen S, Utman N, Karim R J Post Grad Inst2012;27(1)55-62Maternal morbidity associated with emergency versus elective caesarian section.

5. Jindal Promila et al: comparative study of maternal and fetal outcome in elective and emergency CS in Indian OBG 2008.

6. Maike A P C Van Hama et alPete W.J, Van Dongena Jan Mulderh-Maternal consequences of caesarean "European Journal of caesarian sections (CS) performed between 1983-92 in the University Hospital.

7. Samia Hassan, Misbah Kausar Javaid, Sadia Tariq.Emergency Cesarean section; comparative analysis of problems encountered between patients of elective Cesarean section and patient for whom elective Cesarean section was planned but ended up in emergency Professional Med J Apr - Jun 2008; 15(2):211-2.Services Hospital,Lahore

\begin{tabular}{|c|c|c|}
\hline Age of Patients & EM.CS & EL.CS \\
\hline$<20$ years & 4 & 2 \\
\hline $20-30$ years & 78 & 90 \\
\hline$>30$ year & 18 & 8 \\
\hline \multicolumn{3}{|c|}{ Parity of Patients } \\
\hline Primi & 34 & 12 \\
\hline $\mathrm{G}_{2}-\mathrm{G}_{3}$ & 44 & 58 \\
\hline $\mathrm{G}_{4}-\mathrm{G}_{5}$ & 22 & 30 \\
\hline \multicolumn{3}{|c|}{ Mode of Admissions } \\
\hline Through OPD & $20 \%$ & $80 \%$ \\
\hline On Emergency Basis & $70 \%$ & $30 \%$ \\
\hline Table 1: Distribution of Patients According To \\
Age, Parity and Mode of Admission \\
\hline
\end{tabular}

\begin{tabular}{|c|c|c|}
\hline INDICATION & $\begin{array}{c}\text { EMERGENCY } \\
\text { CS } \\
\end{array}$ & $\begin{array}{c}\text { ELECTIVE } \\
\text { CS }\end{array}$ \\
\hline 2 previous $\mathrm{CS}$ & $15(15 \%)$ & $40(40 \%)$ \\
\hline 1 previous CS & $12(12 \%)$ & $24(24 \%)$ \\
\hline PROM & $12(12 \%)$ & 0 \\
\hline Malpresentations & $10(10 \%)$ & $13(13 \%)$ \\
\hline Preeclampsia & $10(10 \%)$ & $3(3 \%)$ \\
\hline $\mathrm{CPD}$ & 0 & $10(10 \%)$ \\
\hline IUGR & $5(5 \%)$ & $10(10 \%)$ \\
\hline APH & $5(5 \%)$ & 0 \\
\hline Failure to Progress & $10(10 \%)$ & 0 \\
\hline Eclampsia & $5(5 \%)$ & 0 \\
\hline Fetal Distress & $8(8 \%)$ & 0 \\
\hline Failed Induction & $5(5 \%)$ & 0 \\
\hline Obstructed labor & $3(3 \%)$ & 0 \\
\hline TOTAL & 100 & 100 \\
\hline \multicolumn{3}{|c|}{ Table 2: Indications of Caeserean Section } \\
\hline
\end{tabular}

\begin{tabular}{|c|c|c|c|}
\hline $\begin{array}{c}\text { Intraoperative } \\
\text { maternal } \\
\text { complication }\end{array}$ & $\begin{array}{c}\text { EMERGENCY } \\
\text { CS }\end{array}$ & $\begin{array}{c}\text { ELECTIVE } \\
\text { CS }\end{array}$ & P VALUE \\
\hline $\begin{array}{c}\text { Difficulty in } \\
\text { intubation }\end{array}$ & $8(8 \%)$ & $2(2 \%)$ & 0.05158 \\
\hline Hemorrhage & $37(37 \%)$ & $14(14 \%)$ & 0.000 \\
\hline Bladder injury & $3(3 \%)$ & $0(0 \%)$ & 0.080 \\
\hline Bowel injury & 0 & 0 & \\
\hline $\begin{array}{c}\text { Extension of } \\
\text { uterine incision }\end{array}$ & $25(25 \%)$ & $10(10 \%)$ & 0.005 \\
\hline Atomic Uterus & $12(12 \%)$ & $4(4 \%)$ & 0.037 \\
\hline $\begin{array}{c}\text { Caesarean } \\
\text { hysterectomy }\end{array}$ & $2(2 \%)$ & 0 & 0.155 \\
\hline $\begin{array}{c}\text { Intra operative } \\
\text { blood } \\
\text { transfusions }\end{array}$ & $35(35 \%)$ & $10(10 \%)$ & 0.000 \\
\hline \multicolumn{3}{|c|}{ Table 3: Intraoperative Maternal Complications } \\
\hline
\end{tabular}

\begin{tabular}{|c|c|c|c|}
\hline $\begin{array}{c}\text { Postoperative } \\
\text { Maternal } \\
\text { Complications }\end{array}$ & $\begin{array}{c}\text { EMERGENCY } \\
\text { CS }\end{array}$ & $\begin{array}{c}\text { ELECTIVE } \\
\text { CS }\end{array}$ & $\begin{array}{c}\text { P } \\
\text { VALUE }\end{array}$ \\
\hline PPH & $28(28 \%)$ & $14(14 \%)$ & 0.015 \\
\hline $\begin{array}{c}\text { Blood } \\
\text { transfusion }\end{array}$ & $30(30 \%)$ & $10(10 \%)$ & 0.000 \\
\hline $\begin{array}{c}\text { Respiratory } \\
\text { infections }\end{array}$ & $14(14 \%)$ & $6(6 \%)$ & 0.059 \\
\hline Burst abdomen & $2(2 \%)$ & 0 & 0.155 \\
\hline UTI & $20(20 \%)$ & $8(8 \%)$ & 0.0144 \\
\hline $\begin{array}{c}\text { Wound } \\
\text { infection }\end{array}$ & $18(18 \%)$ & $6(6 \%)$ & 0.0090 \\
\hline $\begin{array}{c}\text { Postoperative } \\
\text { Hospital Stay } \\
>1 \text { week }\end{array}$ & $20(20 \%)$ & $5(5 \%)$ & 0.001 \\
\hline \multicolumn{4}{|l|}{ Table 4: Postoperative Maternal Complications } \\
\hline
\end{tabular}

